\title{
Prediabetes in Adolescents: Prevalence, Management and Diabetes Prevention Strategies
}

\section{Rebeca Esquivel Zuniga Mark D DeBoer (D)}

Division of Pediatric Endocrinology, Department of Pediatrics, University of Virginia, Charlottesville, VA, USA
Correspondence: Mark D DeBoer Division of Pediatric Endocrinology, University of Virginia, PO Box 800386, Charlottesville, VA, 22903, USA

$\mathrm{Tel}+$ I 434-924-5956

Fax + 434-924-918|

Email deboer@virginia.edu

\begin{abstract}
The ongoing obesity epidemic in children and adolescents has greatly increased the prevalence of related comorbidities. Prediabetes is defined based on levels of fasting glucose, oral glucose tolerance tests or hemoglobin A1c, that are intermediate between normal levels and thresholds that define type 2 diabetes mellitus (T2DM). As such, prediabetes represents a sign of early pathophysiology preceding T2DM development. Recent analyses of data from US adolescents estimate prediabetes to be present in $4-23 \%$ of adolescents, depending on criteria used, with other studies finding an $8 \%$ risk of progression from prediabetes to T2DM over a 3-year period. These data support the importance of intervention to avoid long-term sequelae, focusing on reducing degree of obesity and insulin resistance. Lifestyle modification, with increases in physical activity and dietary improvements, remains the first-line approach. Other interventions are based on additional long-term risks and range from metformin treatment for more moderate cases of prediabetes to bariatric surgery for adolescents with severe obesity and comorbidities. As data accumulate regarding sequelae of T2DM in adolescents, there remains a critical need for prevention of obesity and T2DM throughout childhood, and prediabetes should be a trigger for improving this risk profile.
\end{abstract}

Keywords: prediabetes, pediatrics, obesity, type 2 diabetes mellitus, insulin resistance

\section{Plain Language Summary}

Prediabetes represents blood sugar elevations that are above normal but not yet at thresholds that define type 2 diabetes. Prediabetes can be a precursor to later type 2 diabetes and represents an opportunity to improve lifestyle habits (and sometimes treat with medicines) to avoid ever getting type 2 diabetes.

\section{Introduction}

Obesity is a multifactorial disease that continues to challenge patients, healthcare providers and healthcare systems. ${ }^{1}$ Since 1980 , obesity prevalence has doubled in over 70 countries around the world - particularly rising among more developed countries. ${ }^{2,3}$ In 2015 it is estimated that there were more than 107 million children with obesity worldwide. $^{2}$

As a result of the ongoing obesity epidemic, diseases previously seen almost exclusively in adults are increasingly seen in children and adolescents, including prediabetes and/or type 2 diabetes mellitus (T2DM). ${ }^{4}$ In the United States, using data from the National Health and Nutrition Examination Surveys (NHANES; 2005-2016) approximately $20 \%$ of adolescents aged 12 to 18 years have prediabetes, ${ }^{5}$ while other researchers have estimated that the prevalence of T2DM among adolescents will quadruple by $2050 .^{6}$ 
Unfortunately, most available evidence of T2DM prevention is from adult data, and it is unclear how much can be extrapolated to pediatrics. Therefore, this review will focus on the prevalence and management options of prediabetes in adolescents. Intensive lifestyle programs are still the cornerstones of management of prediabetes in this population; however, in some cases pharmacologic intervention could be considered.

\section{What is Prediabetes? Definitions}

According to guidelines of the American Diabetes Association (ADA), ${ }^{7}$ prediabetes can be diagnosed by one of three laboratory values: (1) elevated fasting glucose of 100 to $125 \mathrm{mg} / \mathrm{dL}(5.6-6.9 \mathrm{mmol} / \mathrm{L})$ or (2) elevated glucose at 2 hours during an oral glucose tolerance test, 140 to $199 \mathrm{mg} / \mathrm{dL}$ (7.8-11.0 mmol/L) or (3) hemoglobin A1C (HbA1C) level between $5.7 \%$ and $6.4 \%(39-46 \mathrm{mmol} / \mathrm{mol}$; Table 1$)$.

\section{Prevalence}

Using criteria from the ADA guidelines, the prevalence of prediabetes in pediatrics is high, particularly among children and adolescents with obesity, in whom the prevalence ranges from $21-40 \%$, depending on the criterion used and the underlying population. 8 , This prevalence of prediabetes in the setting of obesity varies by race/ethnicity, with $54 \%$ of African American adolescents, 28\% of Hispanic adolescents, and $18 \%$ of whites. ${ }^{10}$ Prediabetes is $1.7-2.4$-fold higher in boys than in girls. ${ }^{11}$ Perhaps not surprisingly, the prevalence of prediabetes has continued to rise among adolescents. For example, using the fasting glucose criterion, $1.8 \%$ of adolescents had impaired fasting glucose in 1988-1994, 7.0\% in 1999-2000, and 23\% in 2007-2008. ${ }^{12}$ However, there is variability in estimates obtained using $\mathrm{HbAlc}$ vs fasting glucose, with $4.4 \%$ of US adolescents having prediabetes by HbAlc criteria in $1999-2014$ compared to $15.0 \%$ by

Table I American Diabetic Association Diagnostic Criteria for Normal Glucose, Prediabetes, and Diabetes

\begin{tabular}{|l|l|l|l|}
\hline Diabetes Test & Normal & Prediabetes & Diabetes \\
\hline $\begin{array}{l}\text { Hemoglobin } \mathrm{A}_{\mathrm{Ic}}, \% \\
(\mathrm{HbAlc})\end{array}$ & $<5.7$ & $5.7-6.4$ & $\geq 6.5$ \\
\hline Fasting blood glucose, mg/dL & $<100$ & $100-125$ & $>125$ \\
\hline $\begin{array}{l}\text { Oral glucose } \\
\text { tolerance, } \mathrm{mg} / \mathrm{dL}\end{array}$ & $<140$ & $140-199$ & $\geq 200$ \\
\hline
\end{tabular}

Notes: Data from American Diabetes Association. ${ }^{7}$ fasting glucose levels ${ }^{13}$ - suggesting some criteria may be detecting abnormalities at an earlier stage in disease progression. A school-based study screening Hispanic and Native American middle-school students with multiple T2DM risk factors reported that $43 \%$ had prediabetes by definitions for impaired fasting glucose or impaired glucose tolerance. ${ }^{14}$

\section{Pathophysiology}

The definition of prediabetes is based only on elevated glucose levels, leaving open whether the disorder is seen predominantly in type 1 diabetes mellitus (T1DM) or T2DM. Given that the rise in glucose levels is more rapid in T1DM compared to the more insidious progression of T2DM, there is more time for clinicians to notice glucose abnormalities related with prediabetes in T2DM. ${ }^{15}$ As such, the majority of prediabetes in adolescents (as in adults) appears to be related to T2DM. ${ }^{16}$ In some groups of children and adolescents, up to $45 \%$ of new diabetes cases are T2DM. The SEARCH for Diabetes in Youth Study (a surveillance study in multiple centers in the US) reported that the racial/ethnic breakdown of T2DM incidence per 100,000 adolescents aged 15-19 years was 49.4 cases among American Indians, 22.7 among African Americans, 19.4 among Asians/Pacific Islanders and 8.73 among whites. ${ }^{17}$ There has been an increase in T2DM prevalence worldwide, including in Japan, China, Taiwan, Bangladesh and Australia. ${ }^{18}$

Even though T2DM has increased in the last decades, a complete understanding regarding prediabetes among adolescents is further complicated by the underlying pathophysiology behind the progression from normal glucose regulation to prediabetes to T2DM. In this sense, prediabetes shares overlapping pathophysiology with T2DM. In general the pathophysiology of T2DM includes elements of insulin resistance and inadequate insulin release to overcome this resistance. A decrease in $\beta$-cell function relative to insulin sensitivity was observed by $40 \%$ in obese youth with impaired glucose tolerance (IGT) and by $80 \%$ in children with obesity and T2DM in comparison with their peers with normal glucose tolerance (NGT) ${ }^{19}$ These observations were obtained using hyperglycemic clamp together with the hyperinsulinemiceuglycemic clamp.

Thus, one issue exacerbating prediabetes in adolescence is puberty, which is associated with a significant increase in insulin resistance, potentially contributing to progression from prediabetes to $\mathrm{T} 2 \mathrm{DM} .{ }^{20}$ For example, in one study of 526 adolescents with obesity and impaired 
glucose tolerance followed over an average of 3 years, only $8 \%$ progressed to T2DM, with $65 \%$ converting back to normal glucose tolerance, ${ }^{21}$ while other studies from Europe demonstrated larger percentages of adolescents who reverted to normal glucose tolerance after completion of puberty. ${ }^{22}$ Factors that contribute to progression from a prediabetes to T2DM include the degree of underlying obesity and racial/ethnic background, with non-Hispanic black adolescents exhibiting a significantly higher risk of progressing to T2DM than seen for white adolescents..$^{21,23}$

African-American children have a 4-times higher incidence of developing T2DM in comparison to their Caucasian peers. ${ }^{24}$ In the context of the same degree of insulin sensitivity and after an intravenous glucose challenge, African-American youth have a more pronounced insulin hypersecretion in comparison with white youth. ${ }^{25}$ First-phase and second-phase insulin concentrations were higher in African-American participants in comparison to their white controls, using hyperglycemic clamp. ${ }^{26}$ Also, data evaluating insulin release after IV glucose administration suggest that African-American adolescents are more insulin resistant when compared with Latino adolescents, a difference which is independent of total fat mass as well as visceral fat. ${ }^{27}$ Despite this increased insulin resistance, $\beta$-cell function was flatter in AfricanAmerican compared with Latino adolescents. Hispanic children are also more insulin resistant than Caucasian children and this association is also independent of body fat content. ${ }^{28}$ Data during pubertal maturation in Hispanic youth showed a diminished capacity of $\beta$-cells to respond to the decline in insulin sensitivity during advanced Tanner Stages, increasing the risk of progression of pediatric T2DM in this population. ${ }^{29}$ Other race/ethnicities, including Malaysian, Korean, Taiwanese and Indian, endorse inadequate insulin secretion with even lower BMI that the African-Americans with insulin resistance. Data is even more scarce in adolescents with prediabetes of Asian descent. ${ }^{30}$

While long-term outcome data regarding adolescents with T2DM are limited, the available data has shown another important difference between youth and adult populations with T2DM. T2DM in youth (compared to youth with $\mathrm{T}_{1} \mathrm{DM}^{31,32}$ or to adults with $\left.\mathrm{T} 2 \mathrm{DM}\right)^{33}$ appears to be particularly aggressive and associated with early complications and comorbidities. The Restoring Insulin Secretion (RISE) study described $\sim 25 \%$ lower insulin clearance in adolescents with prediabetes or recent-onset T2DM compared with adults, using the ratio of fasting
C-peptide over insulin as an indirect marker of wholebody insulin clearance. ${ }^{34}$ Hepatic insulin clearance seems to play a major role in the reduction of $\beta$-cell function in obese youth, as it could act as gatekeeper that might avoid the insulin overload to peripheral tissues and $\beta$-cells. ${ }^{35} \mathrm{In}$ the long-term follow up of the Treatment Options for Type 2 Diabetes in Adolescents and Youth (TODAY) cohort, after a mean 13.3 years since T2DM diagnosis, $54 \%$ of participants had experienced diabetic kidney disease, $32 \%$ had experienced nerve disease and $51 \%$ had signs of retinal disease. ${ }^{32}$ In addition, adolescents with T2DM experience more rapid loss of beta cell function and a higher degree of insulin resistance than seen in adults, with a higher rate of failing initial treatment, as demonstrated in the TODAY cohort. ${ }^{36-38}$ Using NHANES data, which included 2843 adolescents aged 12-19 years, adolescents with prediabetes (compared to those without) were more likely to have multiple cardiometabolic risk factors, including obesity, high fasting triglycerides, low HDL-cholesterol, and high liver transaminase levels. ${ }^{13,39}$

Consequently, the concept of prediabetes is widely used to screen for T2DM risk and target preventive treatments. Furthermore significant beta cell destruction may occur before dysglycemia presents; therefore, early recognition and thus early interventions could potentially reduce the risk of potential comorbidities.

\section{Screening for Prediabetes}

Even though no studies in a pediatric population have thus far revealed if early diagnosis of prediabetes improves T2DM long-term outcome, indirect data from adult studies indicates that lifestyle interventions can delay or potentially prevent the progression to T2DM. In adult populations, lifestyle interventions decreased the percentage of patients with prediabetes who progressed over a 4-year period to T2DM from $33 \%$ to $20 \%{ }^{40,41}$

Since generalized screening of children and adolescents with obesity is unlikely to be cost-effective, the ADA and the International Society for Pediatric and Adolescent Diabetes (ISPAD) recommend screening only high-risk patients. ${ }^{42,43}$ These include asymptomatic children and adolescents with obesity after puberty onset or at $\geq 10$ years of age (whichever occurs first) if they have one or more of the following risk factors: (1) family history of T2DM in a first- or second-degree family member; (2) an ethnicity associated with higher risk, including Native American, African American, Hispanic, Asian American, Pacific Islander; (3) history of diabetes in patient's mother 
Table 2 Screening Criteria for Prediabetes and T2DM in Asymptomatic Youth with BMI $\geq 85$ th Percentile

History of Gestational Diabetes during the child's gestation
Family Hisotry of T2DM in first or second-degree family member
Race and/or ethnicity: American Indian, African American, Hispanic,
Asian American and/or Pacific Islander,
Conditions associated with insulin resistance:
-Primary hypertension
-Acanthosis nigricans
-Dyslipidemia
-PCOS
-History of SGA or IUGR

Notes: Youths at puberty are at the highest risk. Screening should begin at the age of 10 years old or at the onset of puberty. Data from Hannon TS. ${ }^{44}$

Abbreviations: PCOS, polycystic ovary syndrome; SGA, small for gestational age; IUGR, intrauterine growth restriction.

or Gestational Diabetes Mellitus (GDM) during the child's gestation; and/or (4) conditions or signs associated with insulin resistance, including hypertension, dyslipidemia, acanthosis nigricans, polycystic ovarian syndrome (PCOS), and small-for-gestational age status at birth (Table 2). ${ }^{44}$ The ADA recommendations advise that this screening should be repeated at least every $2-3$ yearssooner if BMI is increasing; they recommend screening by measuring $\mathrm{HbA1C}$ and FPG or by performing an oral glucose tolerance test (OGTT). To be considered diagnostic, abnormal results have to be confirmed either using the same test on a different day or assessing a different test. ${ }^{42}$

\section{Management}

Given the distinctive characteristics of prediabetes and T2DM in adolescents, pediatric studies are vital. Most of the studies regarding T2DM prevention in pediatric populations include intensive lifestyle programs as their main intervention with only short term evaluations (6 months or less). ${ }^{4}$ However, other studies have evaluated the effect of medications, emphasizing important physiological considerations that may ultimately be shown to prevent or delay diagnosis of T2DM.

\section{Lifestyle Modifications}

In pediatrics, intensive lifestyle programs are the cornerstones in the management of prediabetes. An approach combining dietary and physical activity changes is intervention most likely to be effective. ${ }^{45,46}$ This is many explained by the fact increased energy outflow might lead to a compensatory surge in food consumption, ${ }^{47}$ while isolated caloric restraint would be expected to decrease of the basal metabolic rate. ${ }^{46,48}$

Physical activity has a beneficial effect not only associated through producing weight loss but also on increasing insulin sensitivity independently from the amount of fat tissue. ${ }^{49}$ The Endocrine Society Clinical Practice Guidelines suggest at least 30 minutes of moderate to vigorous physical activity each day with an objective of 60 minutes daily. ${ }^{50}$ Low aerobic and resistance exercises combined together is recommended as this appears to improve insulin sensitivity. ${ }^{46,51}$ Savoye et al ${ }^{52}$ published the results of a 6-month program named "Bright Bodies Healthy Lifestyle" which entailed a randomized control trial of pubertal adolescents with prediabetes diagnosed via 2-hour OGTT glucose levels. These investigators reported that compared to controls, this intensive lifestyle intervention resulted in greater reductions in 2-hour glucose, as well as increased insulin sensitivity. ${ }^{12} \mathrm{~A}$ metaanalysis that evaluated exercise intervention efficacy in obese adolescents showed $40 \%$ improvement in OGTT and 1.02 unit improvement in the homeostasis model of insulin resistance (HOMA-IR), an estimate of insulin resistance based on fasting glucose and insulin. This metaanalysis included 15 trials with a total of 556 participants; however, most interventions were short-term (6-36 weeks). ${ }^{53} \mathrm{~A}$ recent trial published its results from the first 6 months of a 24-month multidisciplinary intervention approach that included a balanced diet and circuit training among 242 children and adolescents aged 6 to 17 years with obesity. ${ }^{54}$ The preliminary data showed improvement in BMI z-score $(-0.14)$ in the exercise group and reduction in adiponectin and waist circumference, however they could find a significant decrease in HOMA-IR. Interestingly they performed a sensitivity analysis based on puberty stage and found significant reduction in HOMA-IR when considering pubertal participants only. ${ }^{54}$

Also, a meta-analysis which included 24 studies that assessed the effects of physical activity on fasting insulin showed positive effects in improving fasting insulin as a marker of pediatric insulin resistance, with the greater effects seem among those with higher BMI z-scores. ${ }^{55}$ Different training interventions such as resistance, aerobic and circuit training were used between studies, as well as non-traditional games to encourage an increase in levels of physical activity. However, the investigators did not find a difference between aerobic and resistance training approaches, suggesting that the most significant factor of an exercise program designed to have an impact on fasting 
insulin and insulin resistance in children and adolescents is not related to a specific type of exercise but just that the children are encouraged to be active somehow. ${ }^{55}$

Furthermore, other health behaviors like food intake and sleeping routines can affect insulin sensitivity. For example, getting less sleep (less than $9 \mathrm{~h}$ /day) and having sleep apnea are associated to insulin resistance. ${ }^{56}$

Regarding dietary intake, the ideal dietary management is still being debated. The chief approach for nutritional approaches in children and adolescents, recommended by the American Academy of Pediatrics, the American Heart Association and the World Health Organization (WHO), is an increase in vegetable and fruit consumption, a decrease in intake of saturated fat, and a complete removal of sugarsweetened beverages. ${ }^{57,58}$ Several studies confirmed that the consumption of food with a higher fiber content was associated with greater insulin sensitivity. ${ }^{59,60}$ A diet with higher fiber intake offers several beneficial effects, such as increased satiety, slower absorption of carbohydrates and the addition of low-energy food to the diet. ${ }^{61}$ Low glycemic index foods reduce blood glucose and insulin postprandial peaks, stimulate fat oxidation and increase satiety, however their effect on insulin resistance is still unclear. ${ }^{62}$

These lifestyle recommendations are sometimes challenging to accomplish, especially for adolescents. Thus, the prevention or treatment of childhood obesity as a means of preventing prediabetes should start as early as possible. As therapeutic methods often only show modest effects, prevention should be the primary objective. The WHO commission advocates individual and community-based prevention strategies to battle the obesity epidemic. ${ }^{63}$ Multiple guidelines have emphasized crucial roles for government, society, and healthcare system policy approaches to take action against childhood obesity. $^{64}$

\section{Metformin}

Metformin, a biguanide derivative, is an oral antihyperglycemic drug that works by inhibiting hepatic glucose production, augmenting peripheral glucose uptake and blocking glucose absorption in the small intestine. ${ }^{65}$ Metformin has also shown an improvement on lipid levels and displays potentially cardio-protective benefits in patients with obesity (see Figure 1).

There is still some controversy regarding the benefit of metformin to improve hyperglycemia or its effects on delaying the onset of T2DM in individuals with prediabetes. ${ }^{65}$ Several clinical trials in populations with prediabetes - including adolescents and adults - have suggested that metformin can delay or even halt the progression from prediabetes to $\mathrm{T}_{2} \mathrm{DM} \mathrm{.}^{34,66}$ Improvements in BMI, fasting serum glucose, fasting insulin, HOMA-IR and lipid levels have been seen in pediatric randomized, controlled trials which include patients on metformin for treatment of obesity associated with insulin resistance. In short-term periods, some of these studies have confirmed that metformin combined with standard lifestyle interventions could reduce body weight and improve insulin sensitivity in children and adolescents with obesity. The majority of investigations have focused on metformin's

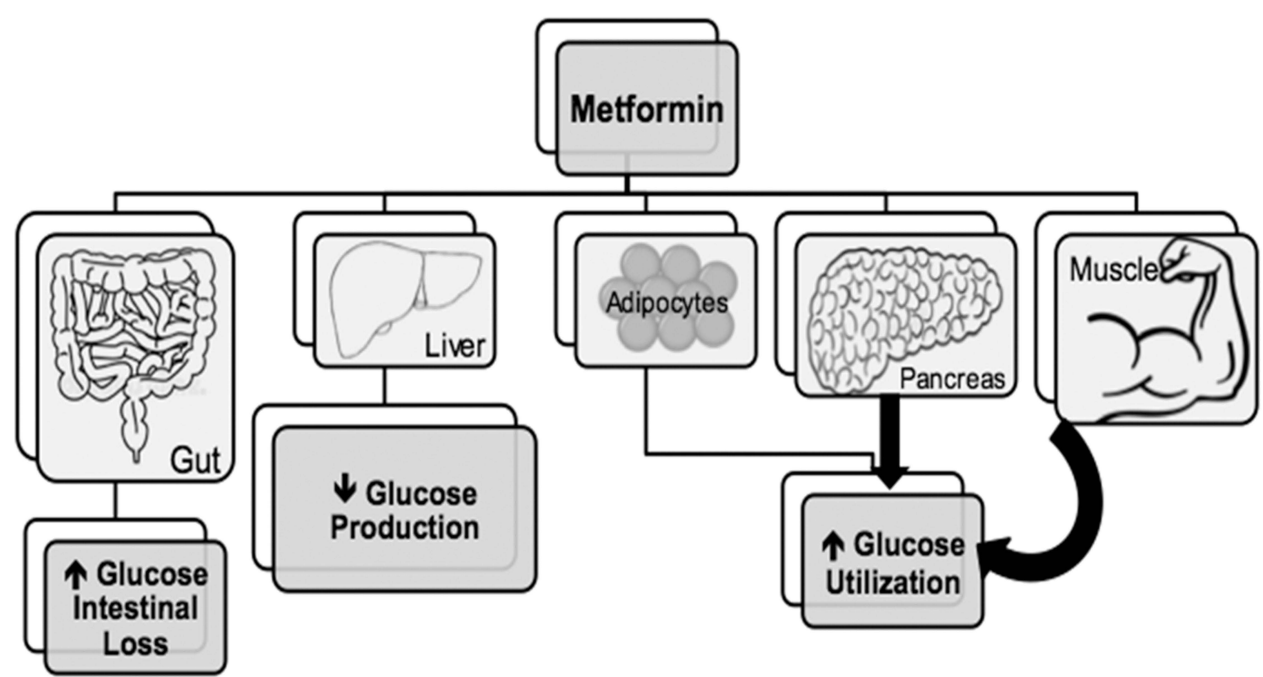

Figure I Main mechanisms of action of metformin in different end-organs. Metformin induces a reduction of hepatic glucose output and an increase in intestinal glucose loss, as well as favorable influences on glucose utilization in beta cells, adipocytes and muscle tissue. 
effects on weight loss, while its effect on insulin resistance has been a less common outcome for these studies. ${ }^{65}$ Furthermore, some of the studies have differing views on whether metformin could improve insulin resistance in obese children and adolescents. ${ }^{67-71}$

A recent meta-analysis of 15 randomized controlled trials assessing treatment of children and/or adolescents with obesity and insulin resistance with metformin $1000 \mathrm{mg}$ to $2000 \mathrm{mg}$ daily for 6 months found that more than half of the studies reported a greater drop in BMI with metformin compared to controls (average decrease of $-1.3 \mathrm{~kg} / \mathrm{m}^{2}$ ), and about one fourth of the trials reported significant decreases in HOMAIR following metformin treatment (average reduction compared to control of -0.6). ${ }^{70,72}$ Additionally, low-dose metfor$\min (850 \mathrm{mg} /$ day $)$ in pediatric patients with obesity and risk indicators for metabolic syndrome was effective, well tolerated, and showed improvements in body composition and inflammation markers, which could potentially translate to long-term health benefits. ${ }^{65,73}$

On the other hand, metformin did not have the same degree of success in T2DM treatment in youth in comparison to the data seen in adults. This was shown in the previously-mentioned TODAY study, a randomized controlled trial of 669 participants from aged 12-17 years of age with recently-diagnosed T2DM (mean 7.8 months). ${ }^{38}$ This cohort experienced a high rate of treatment failure by 5 years with metformin monotherapy, which was more prevalent in pediatric $(51.7 \%)$ versus adult $(21 \%)$ T2DM, despite good medication adherence (80\%). Interestingly, the addition of rosiglitazone, was superior to metformin alone; however, the addition of an intensive lifestyle intervention was not more effective than metformin alone. This study reinforced the idea of premature and rapid deterioration of beta cell function in T2DM in childhood and adolescence compared with adults with newly-diagnosed T2DM. This emphasizes the need for aggressive prevention and eventually combination treatment or insulin therapy early after diagnoses, frequently within a few years. ${ }^{38}$

In conclusion, metformin seems to have a positive effect on insulin sensitivity; however, 2017 Pediatric Obesity Clinical Guidelines from The Endocrine Society and ADA recommendations suggest that it should be introduced only in certain patients. Treatment with metformin should be considered in addition to lifestyle intervention in high risk adolescents. ${ }^{4}$ These high-risk characteristics include a strong family history of T2DM, a BMI greater than $35 \mathrm{~kg} / \mathrm{m}^{2}$, and glycemic criteria for prediabetes (IGT, IFT, and $\mathrm{HbAlC}>5.7 \%$ ). ${ }^{50,74}$ Even so, the long-term benefits of metformin, including diabetes prevention, in children will insulin resistance require further analysis.

\section{Glucagon-Like Peptide (GLP-I) Analogs}

Glucagon-like peptide (GLP-1) is part of the family of incretin hormones, which are released after nutrient intake with the capacity to increase insulin secretory responses during periods associated with hyperglycemia. ${ }^{75}$ It is proposed that there are several mechanisms leading to decreases in blood glucose: (a) actions related to glucose-dependent insulin release, (b) suppression of over-secretion of glucagon (except in the setting of hypoglycemia), and (c) slowing of gastric emptying, which has been associated with clear effects on post-prandial blood glucose excursions. ${ }^{76}$ A large part of the effect of pharmacological doses of GLP-1 appeared to be related to acute reductions in appetite, increased satiety, and reduced caloric intake. ${ }^{75}$

Recently, one of the GLP-1 agonists, liraglutide, was approved for obesity management in children older than 12 years. Liraglutide is a GLP-1 receptor agonist (GLP1RA) that has $97 \%$ homology to endogenous GLP-1 and can be provided as a once-daily subcutaneous injection. ${ }^{77}$ This approval was based on results published last year demonstrating that liraglutide $3.0 \mathrm{mg}$ once daily (along with lifestyle modifications) has an impact on BMI and body weight among adolescents with obesity and difficulty managing their weight with lifestyle modifications alone. Nevertheless, after the 12-week run-in period, there were no substantial differences in blood pressure, lipid abnormalities, fasting glucose levels, or HbA1c. ${ }^{78}$

Even though the FDA approved liraglutide in 2019 for management of T2DM in children greater than 10 years of age, there is a lack of data of its use in pediatric patients with prediabetes. Clinical trials on wider populations are needed to determine its role in the treatment of insulin resistance in children. In addition, the high cost of liraglutide treatment for obesity and the ultimate regain of weight following cessation make it a questionable approach for long-term weight management among adolescents, who would require a lifetime of treatment to sustain the $4 \mathrm{~kg}$ drop in body weight. ${ }^{78}$

\section{Other Medications}

Drugs used for weight loss such as sibutramine and orlistat have also been shown to improve insulin sensitivity in children and adolescents, although their use in this age group is still controversial and continues to require careful thought prior to use. There are also some data that 
peroxisome proliferator-activated receptor (PPAR) gamma agonists could improve insulin sensitivity in adolescents. ${ }^{38}$

Regarding sibutramine, it was evaluated in a randomized, double-blind, placebo-controlled trial which included 82 adolescents from ages of 13 to 17 years, which showed more weight lost on sibutramine in comparison to behavioral therapy and placebo. ${ }^{79}$ After 12 months of follow-up the researchers also reported an improvement in HOMA-IR. ${ }^{79}$ Orlistat was evaluated on 20 adolescents with comorbidities associated with obesity and after 6 months of treatment, participants exhibited improvements in BMI, total and LDL cholesterol, OGTTderived insulin sensitivity and HOMA-IReffects which were greatest among white participants. Nonetheless, the main issue with orlistat is the fact that its tolerability is often very poor due to high rate of flatulence and stool incontinence. ${ }^{80}$

Another study evaluated the use of rosiglitazone in 21 adolescents with obesity with impaired glucose tolerance. More teenagers in the rosiglitazone group returned to normal glucose tolerance vs placebo ( $58 \%$ vs $44 \%$ ), associated with an increase in insulin sensitivity (by hyperinsulinemic-euglycemic clamp) and beta cell function, as measured by OGTT. ${ }^{81}$

\section{Bariatric Surgery}

In many cases, achieving or maintaining weight loss can be challenging, particularly in young populations; therefore, recent guidelines recommend weight loss surgery as an effective therapy for severe obesity disease in adolescents. $^{82}$ Importantly, bariatric surgery results in overall sustained improvements in BMI, while medications only reduce BMI while the patient is taking them. Indications for weight loss surgery include BMI of greater than $35 \mathrm{~kg} / \mathrm{m}^{2}$ with major comorbidities of obesity including T2DM, severe sleep abnormalities (moderate to extreme sleep apnea), pseudotumor cerebri, debilitating orthopedic problems, and non-alcoholic steatohepatitis (NASH).$^{50}$ Adolescents are also candidates for bariatric surgery if they have a BMI of $\geq 40 \mathrm{~kg} / \mathrm{m}^{2}$ with mild obesity complications such as hypertension, lipid abnormalities, orthopedic problems, mild or moderate sleep apnea, and extreme psychological distress due to their obesity. ${ }^{83}$

Along with the reduction on size of gastric size that both procedures entailed, both the roux-and-y gastric by-pass (RYGB) and vertical sleeve gastrectomy (VSG) result in a decrease in appetite and thus improvement in insulin resistance. Both approaches reduce ghrelin concentrations and decrease its orexigenic (appetite increasing) effects and at the same time increase the anorexigenic incretins such as glucagon-like peptide 1 and peptide $Y Y^{84,85}$ as a means of curtailing appetite and increasing insulin sensitivity.

A prospective, multisite observational study which included 5 academic centers, entitled The Teen Longitudinal Assessment of Bariatric Surgery (TeenLABS) study, demonstrated $61 \%$ excess weight loss at 1 year and $62 \%$ excess weight loss at 2 years after bariatric surgery. ${ }^{86}$ Positive effects of RYGB on glucose homeostasis parameters were showed in a study including 22 adolescents with extreme obesity, who were able to achieve a drop in their BMI from 61 to $39 \mathrm{~kg} / \mathrm{m}^{2}$ equivalent to a decrease of $38 \%$ of their BMI. ${ }^{87}$ Encouraging effects of bariatric surgery include reversal of T2DM, a discontinuation of most of diabetes medications, ${ }^{88}$ improvements in glucose homeostasis in populations without diabetes, ${ }^{89}$ and enhanced insulin sensitivity and secretion. ${ }^{90}$

The Teen-LABS study also reported that that $39 \%$ of enrolled patients had more than 4 major obesity-associated comorbidities at baseline. At the time of surgery 20 teens had T2DM and after 3 years of follow-up, 95\% showed remission of T2DM, $76 \%$ remission of prediabetes (which had been noted in 13 of 17 patients), 74\% showed normalization of blood pressure (noted in 56 of 76 with initial hypertension), and a $66 \%$ normalization of their lipid profiles (seen in 84 of 128 patients). ${ }^{91}$

\section{Prevention of Obesity}

Given the solid association between obesity and T2DM, many authors emphasize weight reduction or healthy weight maintenance throughout childhood and teenage years as the ultimate means of preventing T2DM. Table 3 summarizes the main recommendations to prevent obesity. ${ }^{50}$ Overall, the development and execution of obesity prevention policies should 1) address factors contributing to obesity, 2) target obstacles to lifestyle change at personal, environmental and socioeconomic levels, and 3) actively include different levels of parties in government, schools and healthcare centers.

\section{Conclusion}

Prediabetes represents an important warning sign for risk of T2DM associated with childhood obesity-itself an ongoing complex health issue with risk for additional chronic illnesses. Given that the diagnostic criteria and management for prediabetes has been largely determined 
Table 3 Summary of Obesity Prevention Strategies According to 2017 Pediatric Obesity Clinical Guidelines from the Endocrine Society

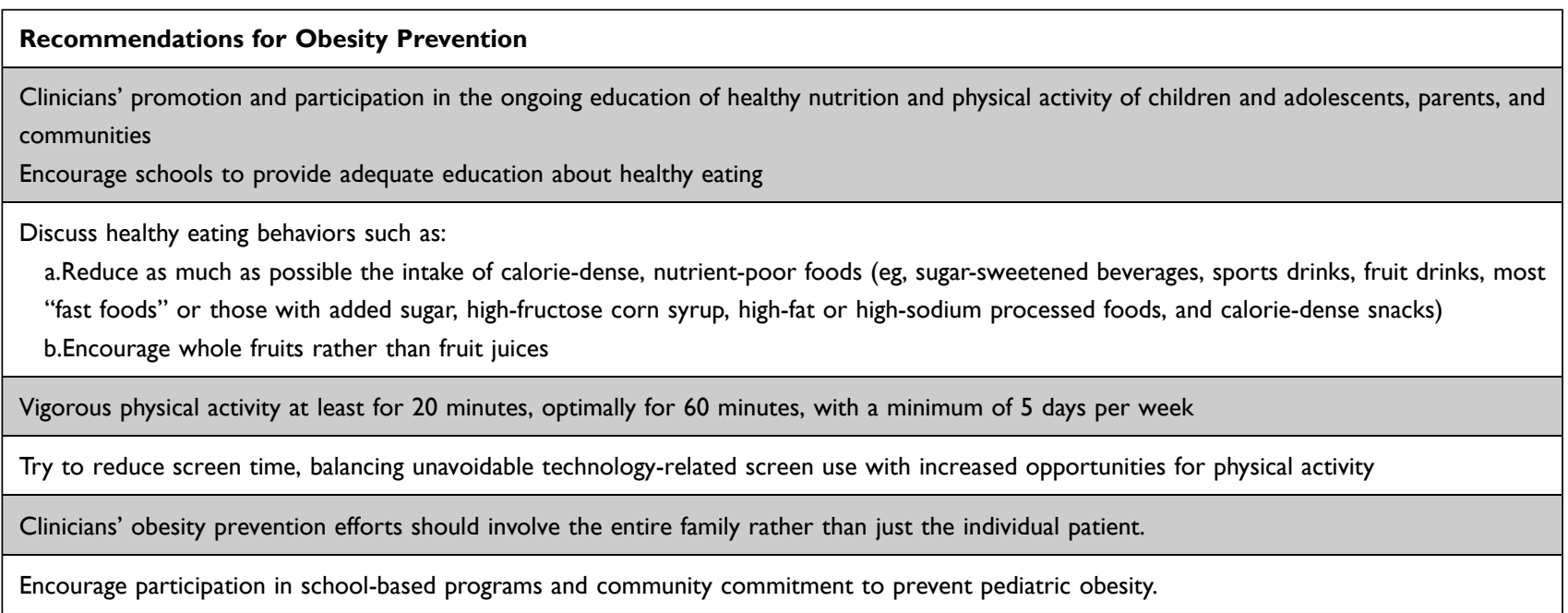

Notes: Data from Styne DM, Arslanian SA, Connor EL, et al. ${ }^{50}$

based on adult data, there is a shortage of long-term data in pediatric populations.

Clinical trials exploring prediabetes treatment in children and adolescents thus far remain small, compared with those in adults, and provide only short-term outcomes. Pediatric populations so far have experienced only modest improvements in insulin sensitivity when receiving interventions such as intensive lifestyle modification, metformin or other insulin sensitizers, and weight loss medications, and it is likely that most of these results originate from weight loss or weight stabilizing benefits of these practices in the short term. ${ }^{12}$ Even though there is no consensus, some providers are more inclined to start treatment with metformin on patients with persistent $\mathrm{HbAlc}$ of $6.0 \%$ to $6.4 \%$, and/or those with impaired fasting glucose or glucose intolerance.

In addition to the need to further delineate the role of medication in addressing prediabetes, additional gaps in current knowledge include the best way to track improvement over time. Recent studies have discussed the further need of new markers of insulin resistance that do not rely on insulin pulsatility, like single-point insulin sensitivity estimator (SPISE) based on BMI, triglycerides and highdensity lipoprotein (HDL) cholesterol. ${ }^{92}$ A metabolic syndrome severity score accurately tracked reduction in the risk for future T2DM and CVD among adults in the Diabetes Prevention Program ${ }^{93,94}$ and was linked to future risk for T2DM and CVD among adolescents. ${ }^{95-98}$ Still additional studies are required to assess the validity of these surrogate markers during long-term treatment of adolescents with prediabetes. Another area for further investigation includes potential mechanisms behind the racial/ethnic disparities, to asses if specific target treatment could work better in certain racial/ethnic groups. Finally, early research has led to questions regarding whether altering the intestinal microbiome may be a future treatment for prediabetes or T2DM. ${ }^{99}$

Furthermore, still the only current universally-accepted management for prediabetes is intensive lifestyle modifications with a combination of increased physical activity, and healthy improved nutrition - an approach that usually requires a high amount of counselling and clinic support. Prevention of obesity in the first place needs to be a focus for all pediatric healthcare providers.

\section{Disclosure}

The authors report no conflicts of interest.

\section{References}

1. Kleinendorst L, Abawi O, van der Voorn B, et al. Identifying underlying medical causes of pediatric obesity: results of a systematic diagnostic approach in a pediatric obesity center. PLoS One. 2020;15 (5):e0232990. doi:10.1371/journal.pone.0232990

2. Afshin A, Forouzanfar MH, Reitsma MB, et al. Health effects of overweight and obesity in 195 countries over 25 years. $N$ Engl J Med. 2017;377(1):13-27.

3. Mengesha Kassie A, Beletew Abate B, Wudu Kassaw M. Education and prevalence of overweight and obesity among reproductive age group women in Ethiopia: analysis of the 2016 Ethiopian demographic and health survey data. BMC Public Health. 2020;20(1):1189. doi:10.1186/s12889-020-08941-w 
4. Dingle E, Brar PC. Prediabetes in Obese Adolescents. Clin Pediatr (Phila). 2017;56(2):115-116. doi:10.1177/0009922816681138

5. Andes LJ, Cheng YJ, Rolka DB, Gregg EW, Imperatore G. Prevalence of prediabetes among adolescents and young adults in the United States, 2005-2016. JAMA Pediatr. 2020;174(2):e194498. doi:10.1001/jamapediatrics.2019.4498

6. Imperatore G, Boyle JP, Thompson TJ, et al. Projections of type 1 and type 2 diabetes burden in the U.S. population aged $<20$ years through 2050: dynamic modeling of incidence, mortality, and population growth. Diabetes Care. 2012;35(12):2515-2520.

7. American Diabetes Association. 2. Classification and diagnosis of diabetes. Diabetes Care. 2021;44(Suppl 1):S15-S33. doi:10.2337/ dc21-S002

8. Li C, Ford ES, Zhao G, Mokdad AH. Prevalence of pre-diabetes and its association with clustering of cardiometabolic risk factors and hyperinsulinemia among U.S. adolescents: National Health and Nutrition Examination Survey 2005-2006. Diabetes Care. 2009;32(2):342-347. doi: $10.2337 / \mathrm{dc} 08-1128$

9. Chan CL, Pyle L, Newnes L, Nadeau KJ, Zeitler PS, Kelsey MM. Continuous glucose monitoring and its relationship to hemoglobin Alc and oral glucose tolerance testing in obese and prediabetic youth. $J$ Clin Endocrinol Metab. 2015;100(3):902-910. doi:10.1210/jc.2014-3612

10. Nowicka P, Santoro N, Liu H, et al. Utility of hemoglobin A(1c) for diagnosing prediabetes and diabetes in obese children and adolescents. Diabetes Care. 2011;34(6):1306-1311. doi:10.2337/ dc10-1984

11. Menke A, Casagrande S, Cowie CC. Prevalence of diabetes in adolescents aged 12 to 19 years in the United States, 2005-2014. JAMA. 2016;316(3):344-345. doi:10.1001/jama.2016.8544

12. Magge SN, Silverstein J, Elder D, Nadeau K, Hannon TS. Evaluation and treatment of prediabetes in youth. J Pediatr. 2020;219:11-22. doi:10.1016/j.jpeds.2019.12.061

13. Lee AM, Fermin CR, Filipp SL, Gurka MJ, DeBoer MD. Examining trends in prediabetes and its relationship with the metabolic syndrome in US adolescents, 1999-2014. Acta Diabetol. 2017;54 (4):373-381. doi:10.1007/s00592-016-0958-6

14. American Diabetes Association. Prevalence of the metabolic syndrome among a racially/ethnically diverse group of U.S eighth-grade adolescents and associations with fasting insulin and homeostasis model assessment of insulin resistance levels. Diabetes Care. 2008;31(10):2020-2025. doi:10.2337/dc08-0411

15. Jacobsen LM, Haller MJ, Schatz DA. Understanding pre-type 1 diabetes: the key to prevention. Front Endocrinol (Lausanne). 2018;9:70. doi:10.3389/fendo.2018.00070

16. Arslanian S, Bacha F, Grey M, Marcus MD, White NH, Zeitler P. Evaluation and management of youth-onset type 2 diabetes: a position statement by the American Diabetes Association. Diabetes Care. 2018;41(12):2648-2668. doi:10.2337/dci18-0052

17. Dabelea D, Bell RA, D'Agostino RB, et al. Incidence of diabetes in youth in the United States. JAMA. 2007;297(24):2716-2724. doi:10.1001/jama.297.24.2716

18. Temneanu OR, Trandafir LM, Purcarea MR. Type 2 diabetes mellitus in children and adolescents: a relatively new clinical problem within pediatric practice. J Med Life. 2016;9(3):235-239.

19. Bacha F, Gungor N, Lee S, Arslanian SA. In vivo insulin sensitivity and secretion in obese youth: what are the differences between normal glucose tolerance, impaired glucose tolerance, and type 2 diabetes? Diabetes Care. 2009;32(1):100-105. doi:10.2337/dc08-1030

20. Moran A, Jacobs DR, Steinberger J, et al. Association between the insulin resistance of puberty and the insulin-like growth factor-I/ growth hormone axis. $J$ Clin Endocrinol Metab. 2002;87 (10):4817-4820. doi:10.1210/jc.2002-020517

21. Galderisi A, Giannini C, Weiss R, et al. Trajectories of changes in glucose tolerance in a multiethnic cohort of obese youths: an observational prospective analysis. Lancet Child Adolesc Health. 2018;2 (10):726-735. doi:10.1016/S2352-4642(18)30235-9
22. Kleber M, deSousa G, Papcke S, Wabitsch M, Reinehr T. Impaired glucose tolerance in obese white children and adolescents: three to five year follow-up in untreated patients. Exp Clin Endocrinol Diabetes. 2011;119(3):172-176. doi:10.1055/s-0030-1263150

23. Serbis A, Giapros V, Kotanidou EP, Galli-Tsinopoulou A, Siomou E. Diagnosis, treatment and prevention of type 2 diabetes mellitus in children and adolescents. World J Diabetes. 2021;12(4):344-365. doi:10.4239/wjd.v12.i4.344

24. Kelsey MM, Geffner ME, Guandalini C, et al. Presentation and effectiveness of early treatment of type 2 diabetes in youth: lessons from the TODAY study. Pediatr Diabetes. 2016;17(3):212-221. doi:10.1111/pedi.12264

25. Michaliszyn SF, Lee S, Bacha F, et al. Differences in $\beta$-cell function and insulin secretion in Black vs. White obese adolescents: do incretin hormones play a role? Pediatr Diabetes. 2017;18(2):143-151. doi:10.1111/pedi.12364

26. Arslanian SA, Saad R, Lewy V, Danadian K, Janosky J. Hyperinsulinemia in African-American children: decreased insulin clearance and increased insulin secretion and its relationship to insulin sensitivity. Diabetes. 2002;51(10):3014-3019. doi:10.2337/ diabetes.51.10.3014

27. Hasson RE, Adam TC, Davis JN, et al. Ethnic differences in insulin action in obese African-American and Latino adolescents. $J$ Clin Endocrinol Metab. 2010;95(8):4048-4051. doi:10.1210/jc.2010-0018

28. Goran MI, Bergman RN, Cruz ML, Watanabe R. Insulin resistance and associated compensatory responses in African-American and Hispanic children. Diabetes Care. 2002;25(12):2184-2190. doi:10.2337/diacare.25.12.2184

29. Goran MI, Shaibi GQ, Weigensberg MJ, Davis JN, Cruz ML. Deterioration of insulin sensitivity and beta-cell function in overweight Hispanic children during pubertal transition: a longitudinal assessment. Int J Pediatr Obes. 2006;1(3):139-145. doi:10.1080/ 17477160600780423

30. Yeow TP, Pacini G, Tura A, et al. Preserved glucagon-like peptide-1 responses to oral glucose, but reduced incretin effect, insulin secretion and sensitivity in young Asians with type 2 diabetes mellitus. BMJ Open Diabetes Res Care. 2017;5(1):e000352. doi:10.1136/ bmjdrc-2016-000352

31. Constantino MI, Molyneaux L, Limacher-Gisler F, et al. Long-term complications and mortality in young-onset diabetes: type 2 diabetes is more hazardous and lethal than type 1 diabetes. Diabetes Care. 2013;36(12):3863-3869. doi:10.2337/dc12-2455

32. Bjornstad P, Drews KL, Caprio S, et al. Long-term complications in youth-onset type 2 diabetes. $N$ Engl J Med. 2021;385(5):416-426.

33. Al-Saeed AH, Constantino MI, Molyneaux L, et al. An inverse relationship between age of type 2 diabetes onset and complication risk and mortality: the impact of youth-onset type 2 diabetes. Diabetes Care. 2016;39(5):823-829. doi:10.2337/dc15-0991

34. Risk Consortium. Metabolic contrasts between youth and adults with impaired glucose tolerance or recently diagnosed type 2 diabetes: I. observations using the hyperglycemic clamp. Diabetes Care. 2018;41(8):1696-1706. doi:10.2337/dc18-0244

35. Galderisi A, Polidori D, Weiss R, et al. Lower insulin clearance parallels a reduced insulin sensitivity in obese youths and is associated with a decline in $\beta$-cell function over time. Diabetes. 2019;68 (11):2074-2084. doi:10.2337/db19-0120

36. Weiss R. Impaired glucose tolerance and risk factors for progression to type 2 diabetes in youth. Pediatr Diabetes. 2007;8:70-75. doi:10.1111/j.1399-5448.2007.00336.x

37. Arslanian S, Kim JY, Nasr A, et al. Insulin sensitivity across the lifespan from obese adolescents to obese adults with impaired glucose tolerance: who is worse off? Pediatr Diabetes. 2018;19 (2):205-211. doi:10.1111/pedi.12562

38. Zeitler P, Hirst K, Pyle L, et al. A clinical trial to maintain glycemic control in youth with type 2 diabetes. $N$ Engl $J$ Med. 2012;366 (24):2247-2256. 
39. Casagrande SS, Menke A, Linder B, Osganian SK, Cowie CC. Cardiovascular risk factors in adolescents with prediabetes. Diabet Med. 2018;35:1202-1209. doi:10.1111/dme.13661

40. Tuso P. Prediabetes and lifestyle modification: time to prevent a preventable disease. Perm J. 2014;18(3):88-93. doi:10.7812/TPP/ 14-002

41. Knowler WC, Barrett-Connor E, Fowler SE, et al. Reduction in the incidence of type 2 diabetes with lifestyle intervention or metformin. $N$ Engl J Med. 2002;346(6):393-403.

42. American Diabetes Association. 13. Children and adolescents. Diabetes Care. 2021;44(Suppl 1):S180-S199. doi:10.2337/dc21S013

43. Mayer-Davis EJ, Kahkoska AR, Jefferies C, et al. ISPAD clinical practice consensus guidelines 2018: definition, epidemiology, and classification of diabetes in children and adolescents. Pediatr Diabetes. 2018;19(Suppl 27):7-19. doi:10.1111/pedi.12773

44. Hannon TS. Promoting prevention, identification, and treatment of prediabetes and type 2 diabetes in youth. Pediatrics. 2020;146(3): e2020010272. doi:10.1542/peds.2020-010272

45. DeBoer MD. Assessing and managing the metabolic syndrome in children and adolescents. Nutrients. 2019;11(8):1788. doi:10.3390/ nu11081788

46. Angi A, Chiarelli F. Chiarelli and diabetes: a sword of damocles for future generations. Biomedicines. 2020;8(11):478. doi:10.3390/ biomedicines 8110478

47. Blundell JE, Stubbs RJ, Hughes DA, Whybrow S, King NA. Cross talk between physical activity and appetite control: does physical activity stimulate appetite? Proc Nutr Soc. 2003;62(3):651-661. doi:10.1079/PNS2003286

48. Martin CK, Heilbronn LK, de Jonge L, et al. Effect of calorie restriction on resting metabolic rate and spontaneous physical activity. Obesity (Silver Spring). 2007;15(12):2964-2973. doi:10.1038/oby.2007.354

49. Bell LM, Watts K, Siafarikas A, et al. Exercise alone reduces insulin resistance in obese children independently of changes in body composition. J Clin Endocrinol Metab. 2007;92(11):4230-4235. doi:10.1210/jc.2007-0779

50. Styne DM, Arslanian SA, Connor EL, et al. Pediatric obesity-assessment, treatment, and prevention: an endocrine society clinical practice guideline. J Clin Endocrinol Metab. 2017;102 (3):709-757.

51. Nassis GP, Papantakou K, Skenderi K, et al. Aerobic exercise training improves insulin sensitivity without changes in body weight, body fat, adiponectin, and inflammatory markers in overweight and obese girls. Metabolism. 2005;54(11):1472-1479. doi:10.1016/j. metabol.2005.05.013

52. Savoye M, Caprio S, Dziura J, et al. Reversal of early abnormalities in glucose metabolism in obese youth: results of an intensive lifestyle randomized controlled trial. Diabetes Care. 2014;37(2):317-324. doi: $10.2337 / \mathrm{dc} 13-1571$

53. Stoner L, Rowlands D, Morrison A, et al. Efficacy of exercise intervention for weight loss in overweight and obese adolescents: meta-analysis and implications. Sports Med. 2016;46 (11):1737-1751. doi:10.1007/s40279-016-0537-6

54. Seo YG, Lim H, Kim Y, et al. Effects of circuit training or a nutritional intervention on body mass index and other cardiometabolic outcomes in children and adolescents with overweight or obesity. PLoS One. 2021;16(1):e245875. doi:10.1371/journal. pone. 0245875

55. Fedewa MV, Gist NH, Evans EM, Dishman RK. Exercise and insulin resistance in youth: a meta-analysis. Pediatrics. 2014;133(1):e163e174. doi:10.1542/peds.2013-2718

56. Sayin FK, Buyukinan M. Sleep duration and media time have a major impact on insulin resistance and metabolic risk factors in obese children and adolescents. Child Obes. 2016;12(4):272-278. doi:10.1089/chi.2015.0126
57. DeBoer MD. Obesity, systemic inflammation, and increased risk for cardiovascular disease and diabetes among adolescents: a need for screening tools to target interventions. Nutrition. 2013;29 (2):379-386. doi:10.1016/j.nut.2012.07.003

58. Scharf RJ, DeBoer MD. Sugar-sweetened beverages and children's health. Annu Rev Public Health. 2016;37:273-293. doi:10.1146/ annurev-publhealth-032315-021528

59. Carlson JJ, Eisenmann JC, Norman GJ, Ortiz KA, Young PC. Dietary fiber and nutrient density are inversely associated with the metabolic syndrome in US adolescents. $J$ Am Diet Assoc. 2011;111 (11):1688-1695. doi:10.1016/j.jada.2011.08.008

60. Davis JN, Alexander KE, Ventura EE, Toledo-Corral CM, Goran MI. Inverse relation between dietary fiber intake and visceral adiposity in overweight Latino youth. Am J Clin Nutr. 2009;90(5):1160-1166. doi:10.3945/ajen.2009.28133

61. Lin Y, Huybrechts I, Vereecken C, et al. Dietary fiber intake and its association with indicators of adiposity and serum biomarkers in European adolescents: the HELENA study. Eur J Nutr. 2015;54 (5):771-782. doi:10.1007/s00394-014-0756-2

62. Thomas DE, Elliott EJ, Baur L. Low glycaemic index or low glycaemic load diets for overweight and obesity. Cochrane Database Syst Rev. 2007;(3):CD005105. doi:10.1002/14651858.CD005105.pub2

63. World Health Organization. Population-based approaches to childhood obesity prevention; 2012.

64. Ferreira RJ, Nogueira T, Dias da Silva V, et al. A school-based intervention for a better future: study protocol of Sintra Grows Healthy. BMC Public Health. 2020;20(1):1615. doi:10.1186/s12889020-09715-0

65. Soliman A, De Sanctis V, Alaaraj N, Hamed N. The clinical application of metformin in children and adolescents: a short update. Acta Biomed. 2020;91(3):e2020086.

66. Khokhar A, Umpaichitra V, Chin VL, Perez-Colon S. Metformin use in children and adolescents with prediabetes. Pediatr Clin North Am. 2017;64(6):1341-1353. doi:10.1016/j.pcl.2017.08.010

67. Tagi VM, Giannini C, Chiarelli F. Insulin resistance in children. Front Endocrinol (Lausanne). 2019;10:342. doi:10.3389/ fendo.2019.00342

68. Kay JP, Alemzadeh R, Langley G, D'Angelo L, Smith P, Holshouser S. Beneficial effects of metformin in normoglycemic morbidly obese adolescents. Metabolism. 2001;50(12):1457-1461. doi:10.1053/meta.2001.28078

69. Srinivasan S, Ambler GR, Baur LA, et al. Randomized, controlled trial of metformin for obesity and insulin resistance in children and adolescents: improvement in body composition and fasting insulin. $J$ Clin Endocrinol Metab. 2006;91(6):2074-2080. doi:10.1210/ jc.2006-0241

70. Mead E, Atkinson G, Richter B, et al. Drug interventions for the treatment of obesity in children and adolescents. Cochrane Database Syst Rev. 2016;11:CD012436.

71. Atabek ME, Pirgon O. Use of metformin in obese adolescents with hyperinsulinemia: a 6-month, randomized, double-blind, placebo-controlled clinical trial. $J$ Pediatr Endocrinol Metab. 2008;21(4):339-348. doi:10.1515/JPEM.2008.21.4.339

72. Lentferink YE, Knibbe CAJ, van der Vorst MMJ. Efficacy of metformin treatment with respect to weight reduction in children and adults with obesity: a systematic review. Drugs. 2018;78 (18):1887-1901. doi:10.1007/s40265-018-1025-0

73. Bassols J, Martínez-Calcerrada JM, Osiniri I, et al. Effects of metformin administration on endocrine-metabolic parameters, visceral adiposity and cardiovascular risk factors in children with obesity and risk markers for metabolic syndrome: a pilot study. PLoS One. 2019;14(12):e0226303. doi:10.1371/journal.pone.0226303

74. American Diabetes Association. (3) Prevention or delay of type 2 diabetes. Diabetes Care. 2021;44(Suppl):S34-39. doi:10.2337/dc21S003 
75. Nauck MA, Quast DR, Wefers J, Meier JJ. GLP-1 receptor agonists in the treatment of type 2 diabetes - state-of-the-art. Mol Metab. 2021;46:101102. doi:10.1016/j.molmet.2020.101102

76. Flint A, Raben A, Astrup A, Holst JJ. Glucagon-like peptide 1 promotes satiety and suppresses energy intake in humans. $J$ Clin Invest. 1998;101(3):515-520. doi:10.1172/JCI990

77. Holst JJ. The physiology of glucagon-like peptide 1. Physiol Rev. 2007;87(4):1409-1439. doi:10.1152/physrev.00034.2006

78. Kelly AS, Auerbach P, Barrientos-Perez M, et al. A randomized, controlled trial of liraglutide for adolescents with obesity. $N$ Engl $J$ Med. 2020;382(22):2117-2128. doi:10.1056/NEJMoa1916038

79. Berkowitz RI, Wadden TA, Tershakovec AM, Cronquist JL. Behavior therapy and sibutramine for the treatment of adolescent obesity: a randomized controlled trial. JAMA. 2003;289(14):1805-1812. doi:10.1001/jama.289.14.1805

80. McDuffie JR, Calis KA, Uwaifo GI, et al. Efficacy of orlistat as an adjunct to behavioral treatment in overweight African American and Caucasian adolescents with obesity-related co-morbid conditions. J Pediatr Endocrinol Metab. 2004;17(3):307-319. doi:10.1515/ JPEM.2004.17.3.307

81. Cali AM, Pierpont BM, Taksali SE, et al. Rosiglitazone improves glucose metabolism in obese adolescents with impaired glucose tolerance: a pilot study. Obesity (Silver Spring). 2011;19(1):94-99. doi:10.1038/oby.2010.109

82. Pratt JSA, Browne A, Browne NT, et al. ASMBS pediatric metabolic and bariatric surgery guidelines, 2018. Surg Obes Relat Dis. 2018;14 (7):882-901. doi:10.1016/j.soard.2018.03.019

83. Sarr MG. Medical indications for weight-loss surgery in adolescents: but are there other equally important indications? JAMA Pediatr. 2014;168(1):11-12. doi:10.1001/jamapediatrics.2013.4496

84. Karamanakos SN, Vagenas K, Kalfarentzos F, Alexandrides TK. Weight loss, appetite suppression, and changes in fasting and postprandial ghrelin and peptide-YY levels after Roux-en-Y gastric bypass and sleeve gastrectomy: a prospective, double blind study. Ann Surg. 2008;247(3):401-407. doi:10.1097/SLA.0b013e318156f012

85. Ramón JM, Salvans S, Crous X, et al. Effect of Roux-en-Y gastric bypass vs sleeve gastrectomy on glucose and gut hormones: a prospective randomised trial. $J$ Gastrointest Surg. 2012;16 (6):1116-1122. doi:10.1007/s11605-012-1855-0

86. Alqahtani AR, Antonisamy B, Alamri H, Elahmedi M, Zimmerman VA. Laparoscopic sleeve gastrectomy in 108 obese children and adolescents aged 5 to 21 years. Ann Surg. 2012;256 (2):266-273. doi:10.1097/SLA.0b013e318251e92b

87. Lawson ML, Kirk S, Mitchell T, et al. One-year outcomes of Roux-en-Y gastric bypass for morbidly obese adolescents: a multicenter study from the Pediatric Bariatric Study Group. J Pediatr Surg. 2006;41 (1):137-143. doi:10.1016/j.jpedsurg.2005.10.017

88. Inge TH, Miyano G, Bean J, et al. Reversal of type 2 diabetes mellitus and improvements in cardiovascular risk factors after surgical weight loss in adolescents. Pediatrics. 2009;123(1):214-222. doi:10.1542/peds.2008-0522
89. Korner J, Bessler M, Cirilo LJ, et al. Effects of Roux-en-Y gastric bypass surgery on fasting and postprandial concentrations of plasma ghrelin, peptide YY, and insulin. J Clin Endocrinol Metab. 2005;90 (1):359-365. doi:10.1210/jc.2004-1076

90. Inge TH, Prigeon RL, Elder DA, et al. Insulin sensitivity and $\beta$-cell function improve after gastric bypass in severely obese adolescents. $J \quad$ Pediatr. 2015;167(5):1042-1048.e1041. doi:10.1016/j.jpeds.20 15.08.020

91. Rosenthal RJ, Diaz AA, Arvidsson D, et al. International Sleeve Gastrectomy Expert Panel Consensus Statement: best practice guidelines based on experience of $>12,000$ cases. Surg Obes Relat Dis. 2012;8(1):8-19. doi:10.1016/j.soard.2011.10.019

92. Correa-Burrows P, Blanco E, Gahagan S, Burrows R. Validity assessment of the single-point insulin sensitivity estimator (spise) for diagnosis of cardiometabolic risk in post-pubertal hispanic adolescents. Sci Rep. 2020;10(1):14399. doi:10.1038/s41598-020-71074-y

93. DeBoer MD, Filipp SL, Gurka MJ. Use of a metabolic syndrome severity $\mathrm{Z}$ score to track risk during treatment of prediabetes: an analysis of the diabetes prevention program. Diabetes Care. 2018;41(11):2421-2430. doi:10.2337/dc18-1079

94. Gurka MJ, Lilly CL, Norman OM, DeBoer MD. An examination of sex and racial/ethnic differences in the metabolic syndrome among adults: a confirmatory factor analysis and a resulting continuous severity score. Metabolism. 2014;63(2):218-225. doi:10.1016/j. metabol.2013.10.006

95. DeBoer MD, Gurka MJ, Woo JG, Morrison JA. Severity of metabolic syndrome as a predictor of cardiovascular disease between childhood and adulthood: the Princeton Lipid Research Cohort Study. J Amer Coll Card. 2015;66(6):755-757. doi:10.1016/j.jacc.2015.05.061

96. DeBoer MD, Gurka MJ, Woo JG, Morrison JA. Severity of the metabolic syndrome as a predictor of type 2 diabetes between childhood and adulthood: the Princeton Lipid Research Cohort Study. Diabetologia . 2015;58(12):2745-2752. doi:10.1007/s00125-0153759-5

97. DeBoer MD, Gurka MJ, Morrison JA, Woo JG. Inter-relationships between the severity of metabolic syndrome, insulin and adiponectin and their relationship to future type 2 diabetes and cardiovascular disease. Int J Obes (Lond). 2016;40(9):1353-1359. doi:10.1038/ ijo.2016.81

98. Gurka MJ, Ice CL, Sun SS, DeBoer MD. A confirmatory factor analysis of the metabolic syndrome in adolescents: an examination of sex and racial/ethnic differences. Cardiovasc Diabetol. 2012;11:128. doi:10.1186/1475-2840-11-128

99. Ghorbani Y, Schwenger KJP, Allard JP. Manipulation of intestinal microbiome as potential treatment for insulin resistance and type 2 diabetes. Eur J Nutr. 2021;60(5):2361-2379. doi:10.1007/s00394021-02520-4

Diabetes, Metabolic Syndrome and Obesity: Targets and Therapy

Dovepress

\section{Publish your work in this journal}

Diabetes, Metabolic Syndrome and Obesity: Targets and Therapy is an international, peer-reviewed open-access journal committed to the rapid publication of the latest laboratory and clinical findings in the fields of diabetes, metabolic syndrome and obesity research. Original research, review, case reports, hypothesis formation, expert opinion and commentaries are all considered for publication. The manuscript management system is completely online and includes a very quick and fair peer-review system, which is all easy to use. Visit http://www.dovepress.com/testimonials.php to read real quotes from published authors. 